\title{
palacio de los deportes
}

F. CANDELA OUTERIÑO,

A. PEYRI MACIA

y E. CASTAÑNDA TAMBORRELL, arquitectos

\section{simopsis}

Este edificio, construido para los Juegos Olímpicos de México, fue destinado a los juegos de baloncesto, pero al proyectarlo se previó que posteriormente pudiera servir para posteriormente pudiera servir para múltiples usos: celebración de comhielo, teatro, circo, etc. Tiene capacidad para 19.824 espectadores sentados.

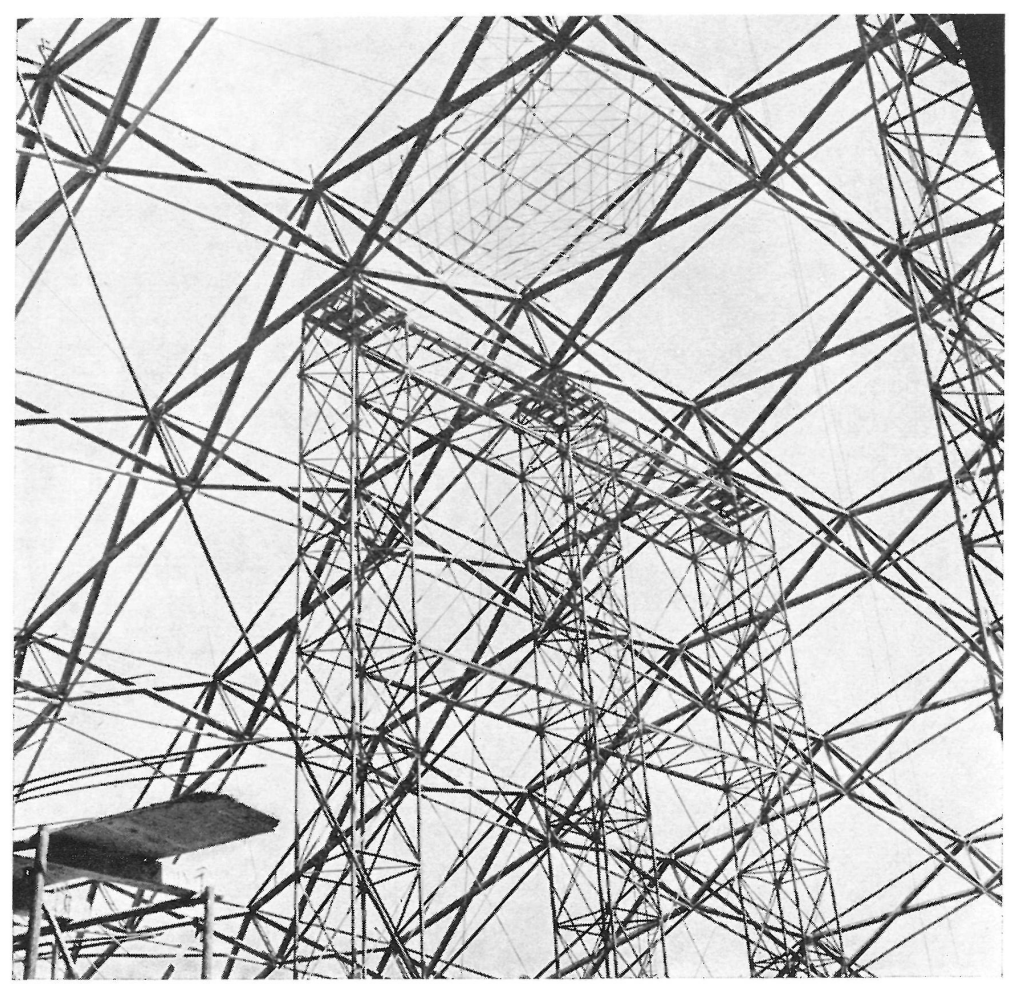

Su planta es circular, con un diámetro total de $180 \mathrm{~m}$, y está organizada en tres niveles:

- en el nivel inferior se alojan: los servicios para deportistas, prensa y organización del Certamen Olímpico;

- el nivel principal alberga: los vestíbulos, escaleras y accesos a gradería baja y media;

- y en el nivel superior se distribuyen: los servicios para público, palcos y accesos a gradería media y alta.

En este Palacio de los Deportes destaca su estructura general que fue considerada, desde la fase del proyecto, como el elemento dominante de la composición, y el determinante de su sentido plástico y espacial.

Dentro de la serie de instalaciones deportivas que fueron construidas para los recientemente celebrados Juegos Olímpicos de México figura este Palacio de Deportes, situado en terrenos del gran conjunto deportivo de la "Magdalena Mixhuca», en la esquina que llaman la Avenida Río Churubusco y Viaducto Miguel Alemán, que unen satisfactoriamente al ya citado Palacio de Deportes con la Villa Olímpica, con las demás instalaciones olímpicas y con la zona hotelera de la Ciudad de México.

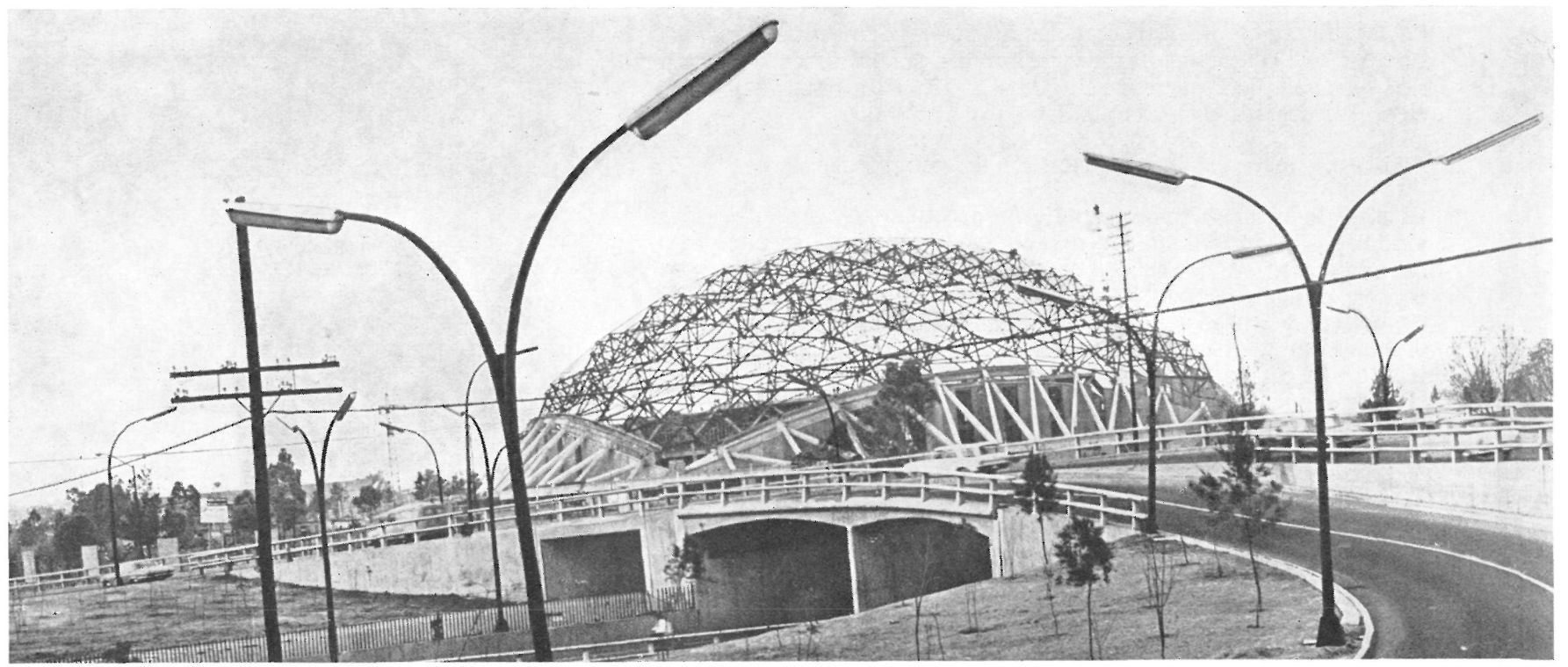




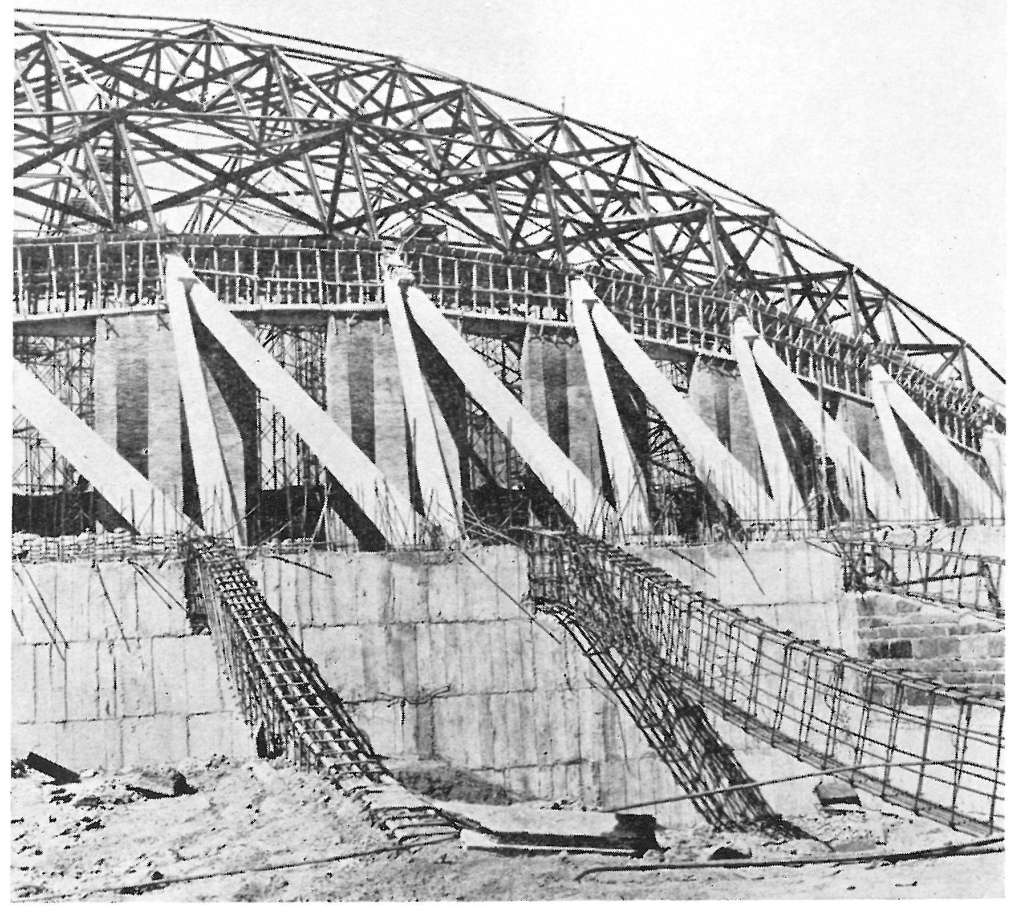

\section{de \\ fases \\ construceción}

Dista de la Villa Olímpica $22 \mathrm{~km}$ y $7 \mathrm{~km}$ de la Plaza Mayor, y cuenta con estacionamiento para unos 2.000 automóviles.

Fue destinado a los juegos de baloncesto, pero se proyectó pensando que posteriormente pudiera utilizarse para la celebración de: combates de boxeo; balonvolea; lucha; judo; gimnasia; levantamiento de peso; atletismo a cubierto, en pista y campo; espectáculos sobre hielo; teatro; circo; etc.

Como datos característicos, siempre útiles a la hora de proyectar una construcción de este tipo, señalaremos que tiene una capacidad de 19.824 asientos, que en la Olimpíada fueron destinados: 18.706 para el público; 12 al palco presidencial; 103 a la tribuna $\mathrm{A}$, azul; 151 a la tribuna $\mathrm{B}$, gris; 158 a la tribuna C, rojo; 35 a la tribuna $\mathrm{D}$, amarillo; 96 a la zona de periodistas con mesa; 78 para periodistas sin mesa; 122 para radio y T.V.; 54 para fotógrafos; 350 a la tribuna E, verde; 236 a la tribuna F, café; y 61 en otras zonas.

El edificio, de planta circular, tiene un diámetro total de $180 \mathrm{~m}$ y un espacio libre en la sala de espectáculos de $166 \mathrm{~m}$. La superficie construida es de $27.461 \mathrm{~m}^{2}$.

Está organizado en tres niveles:

- el nivel inferior aloja: los servicios generales para su funcionamiento, y ubicadas en el lado sur fueron localizadas las oficinas de las Federaciones Nacional e Internacional y las propias oficinas del Comité

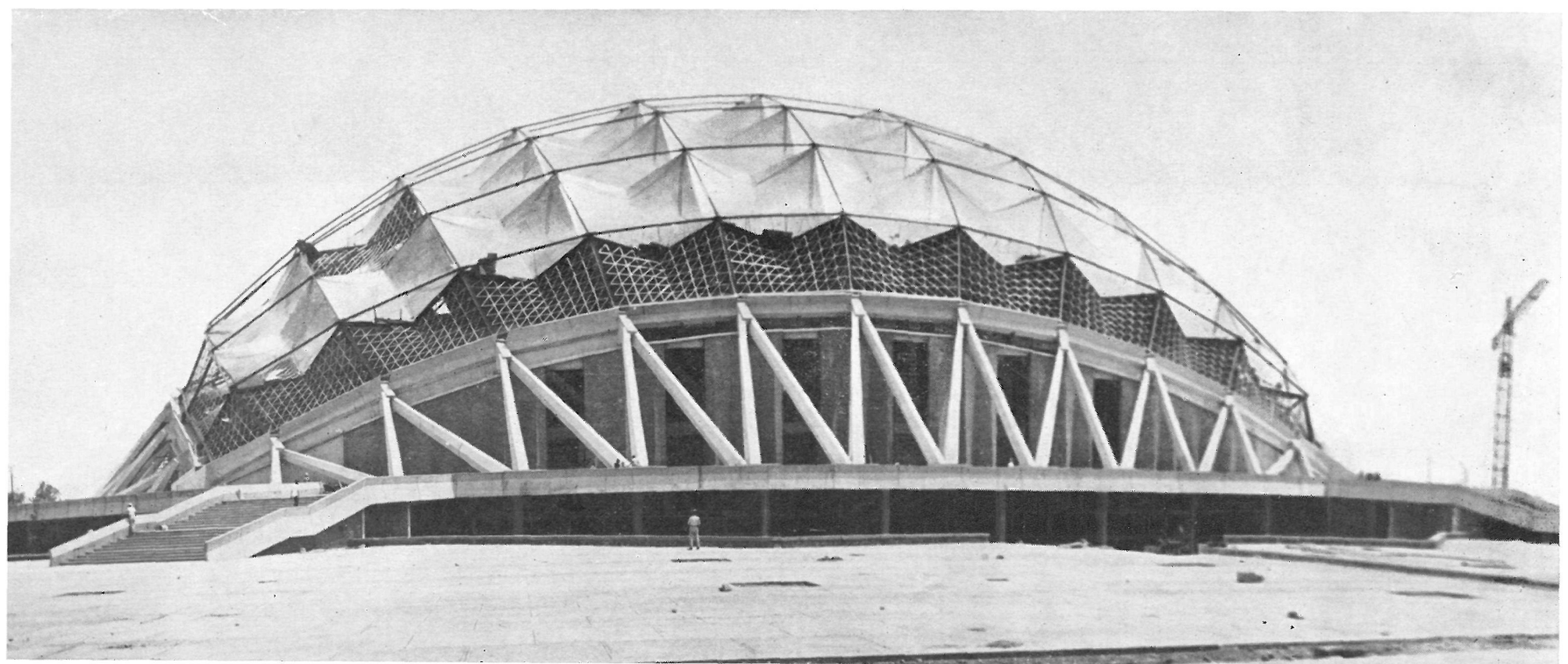



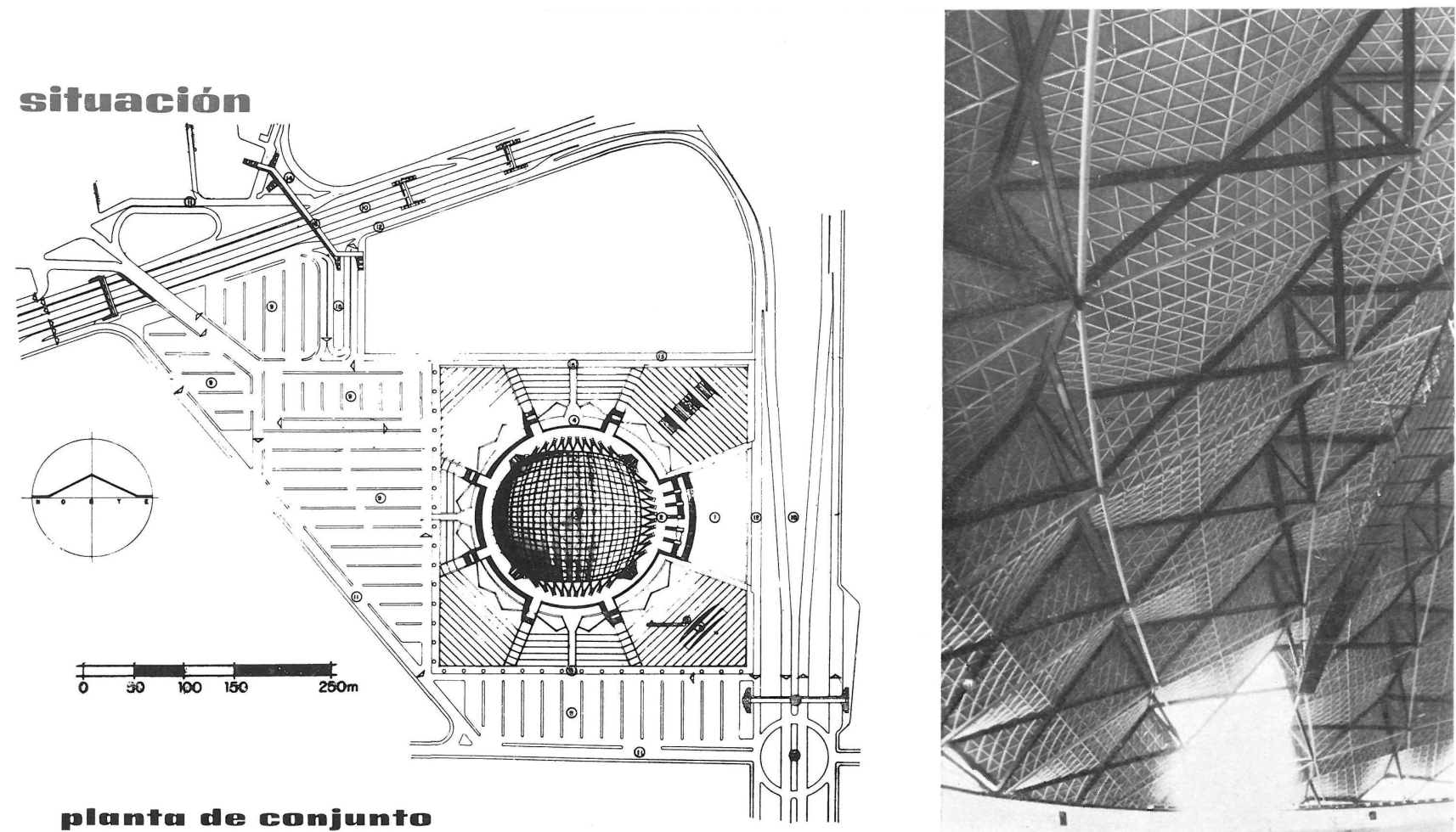

1. Plaza.-2. Plataforma de acceso.-3. Palacio.-4. Calle perimetral.-5. Acceso de servicio.-6. Espejo de agua.-7. Casa de maquinas.-8. Tanque elevado.-9. Esta12. Calle lateral - 13 Calle de servicio - 14. Terminal de autobuses. - 15. Terminal de taxis - 16. Paso de peatones - 17. Glorieta - 18. Vía rápida Av Río Churubusco.

Organizador. Esta zona cuenta con: sala de Juntas; oficinas privadas para las Federaciones, y de control y organización de actos; sanitarios; servicios de cafetería, etc.;

- el nivel principal alberga: los vestíbulos, escaleras y accesos a gradería baja y media;

- y el nivel superior contiene: los servicios para el público, palcos y accesos a gradería media y alta.
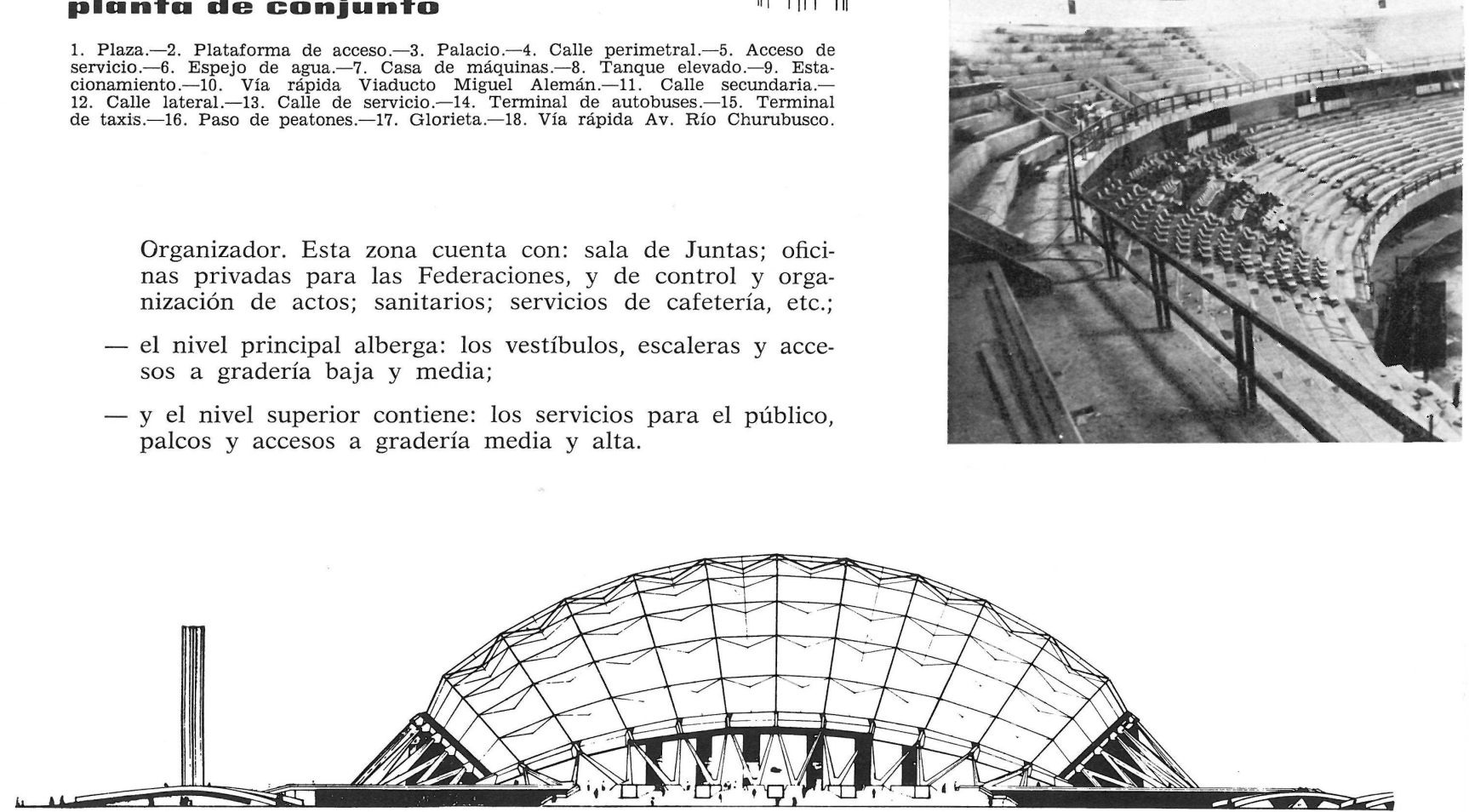

\section{alzado}

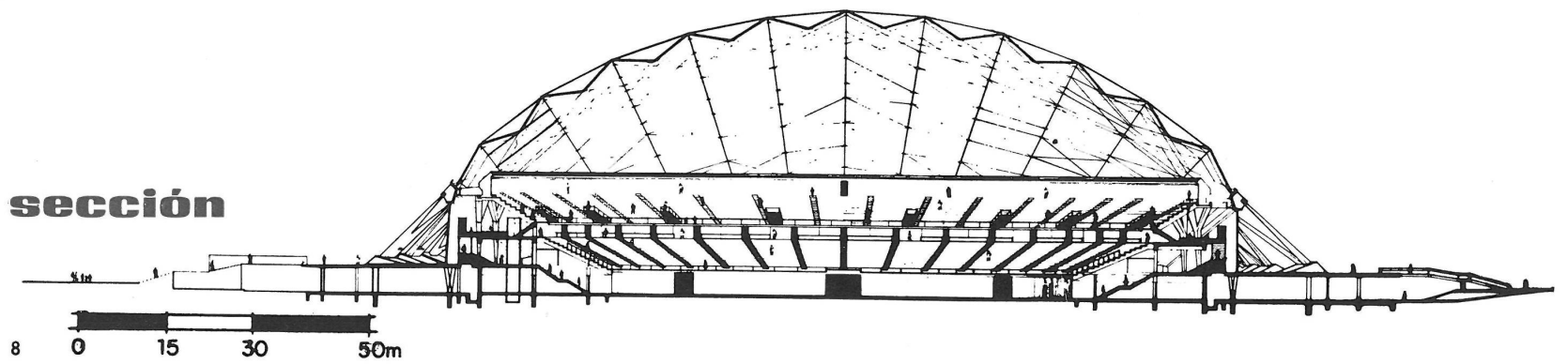



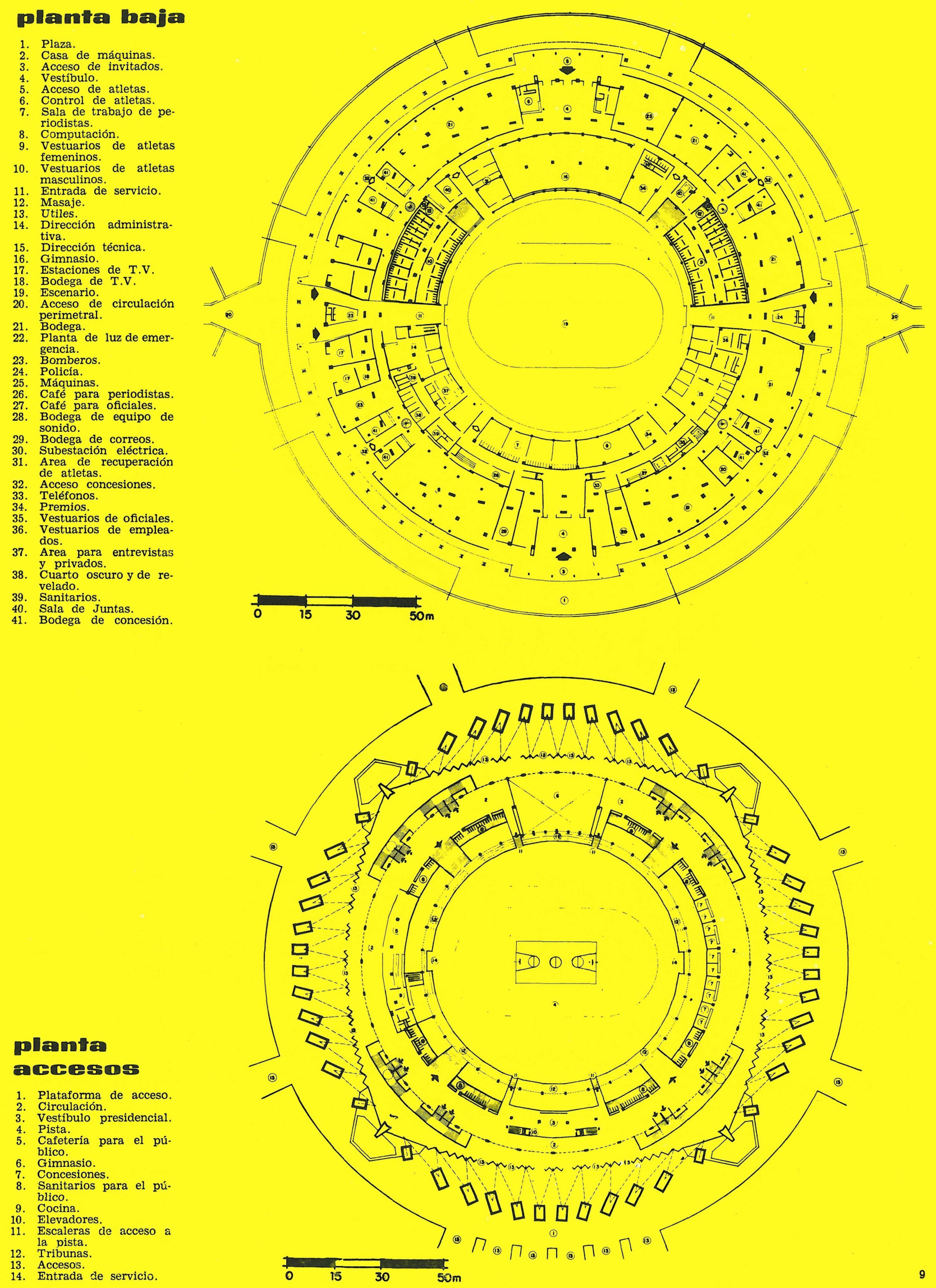


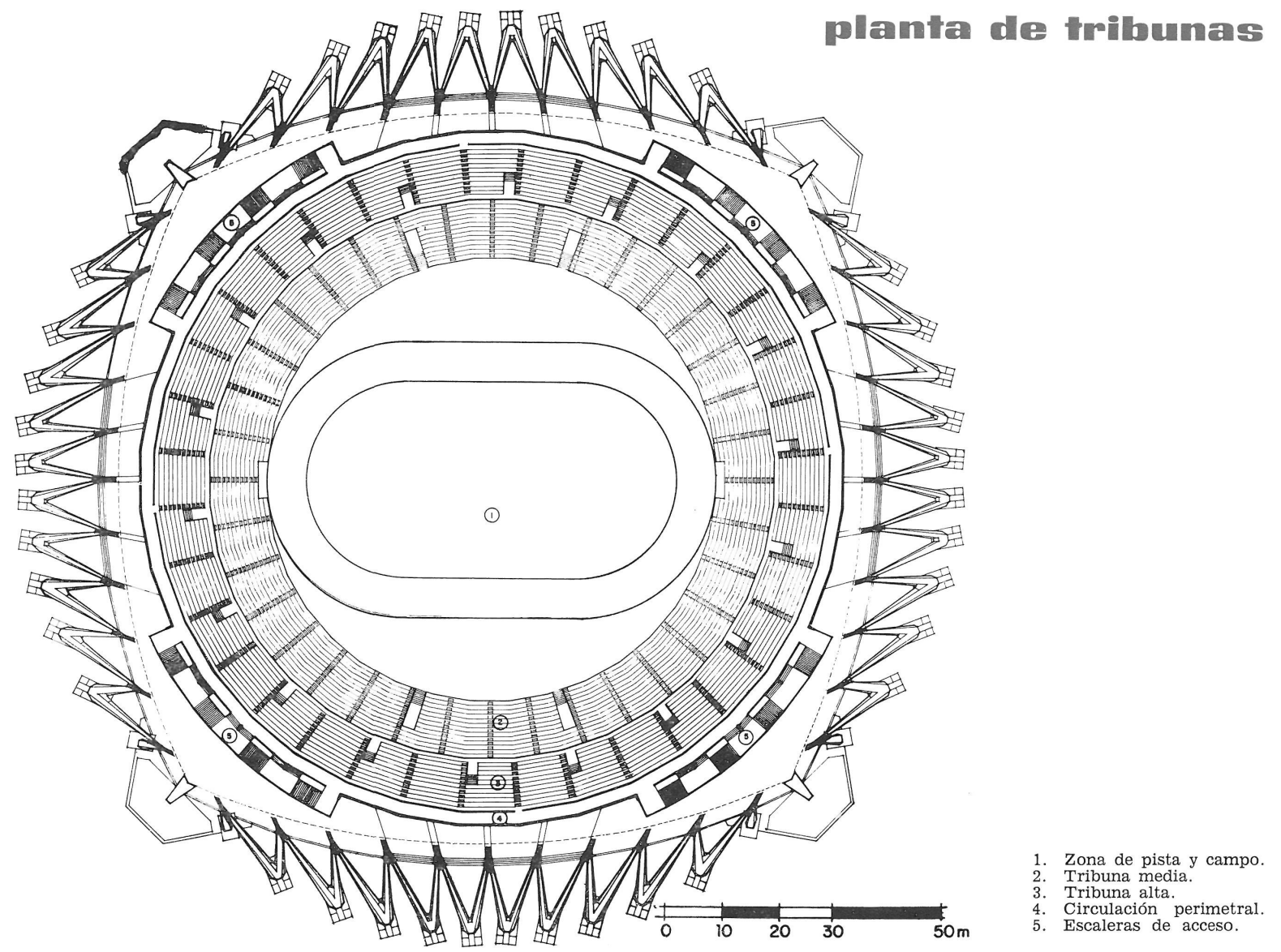

Podemos resaltar entre las características constructivas: que el tipo de cimentación elegido —cimentación mixta, con abundante pilotaje - permitirá que el edificio siga los movimientos del terreno circundante al consolidarse la arcilla, y se espera reducir, al mínimo, los desplazamientos diferenciales de la estructura. Sobre los pilotes se apoya una retícula de vigas y losa de hormigón armado.
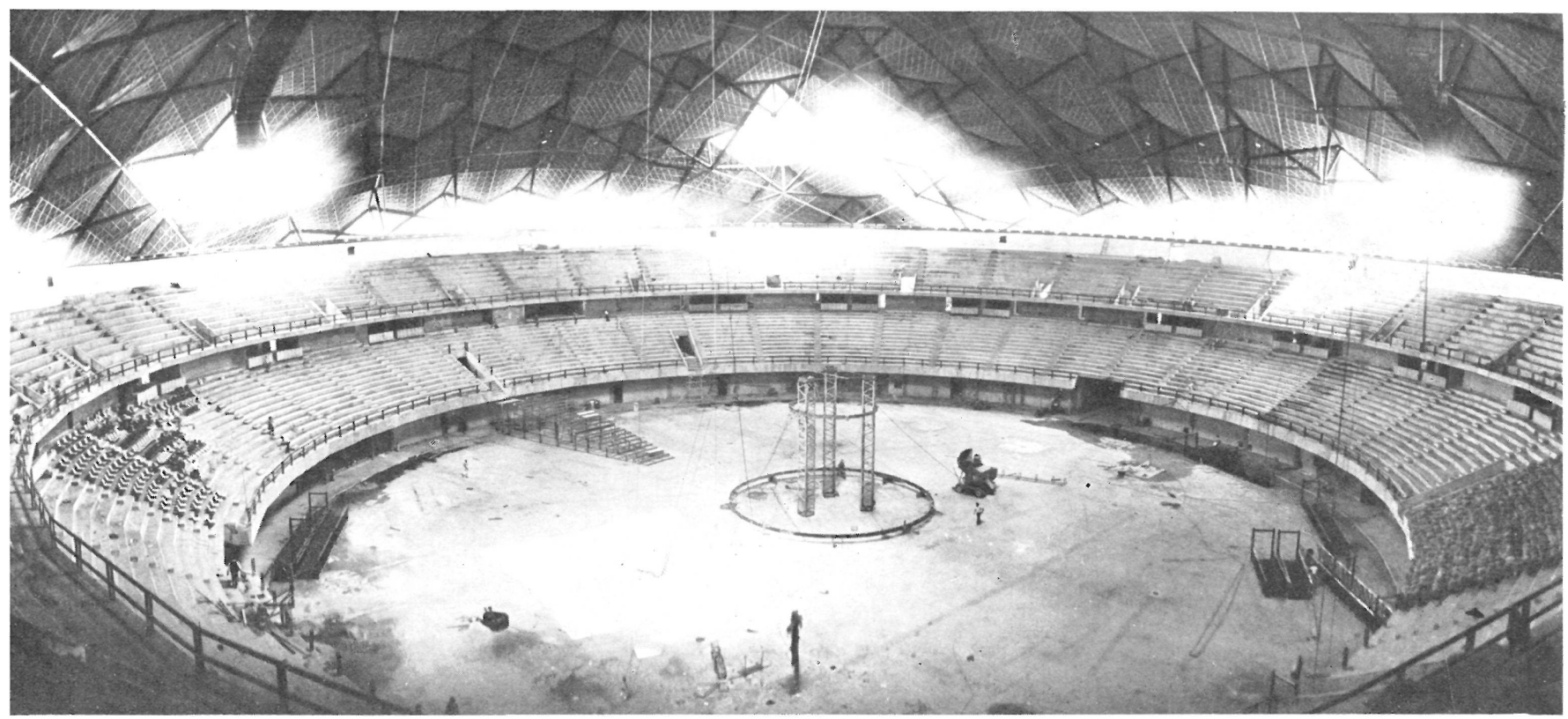

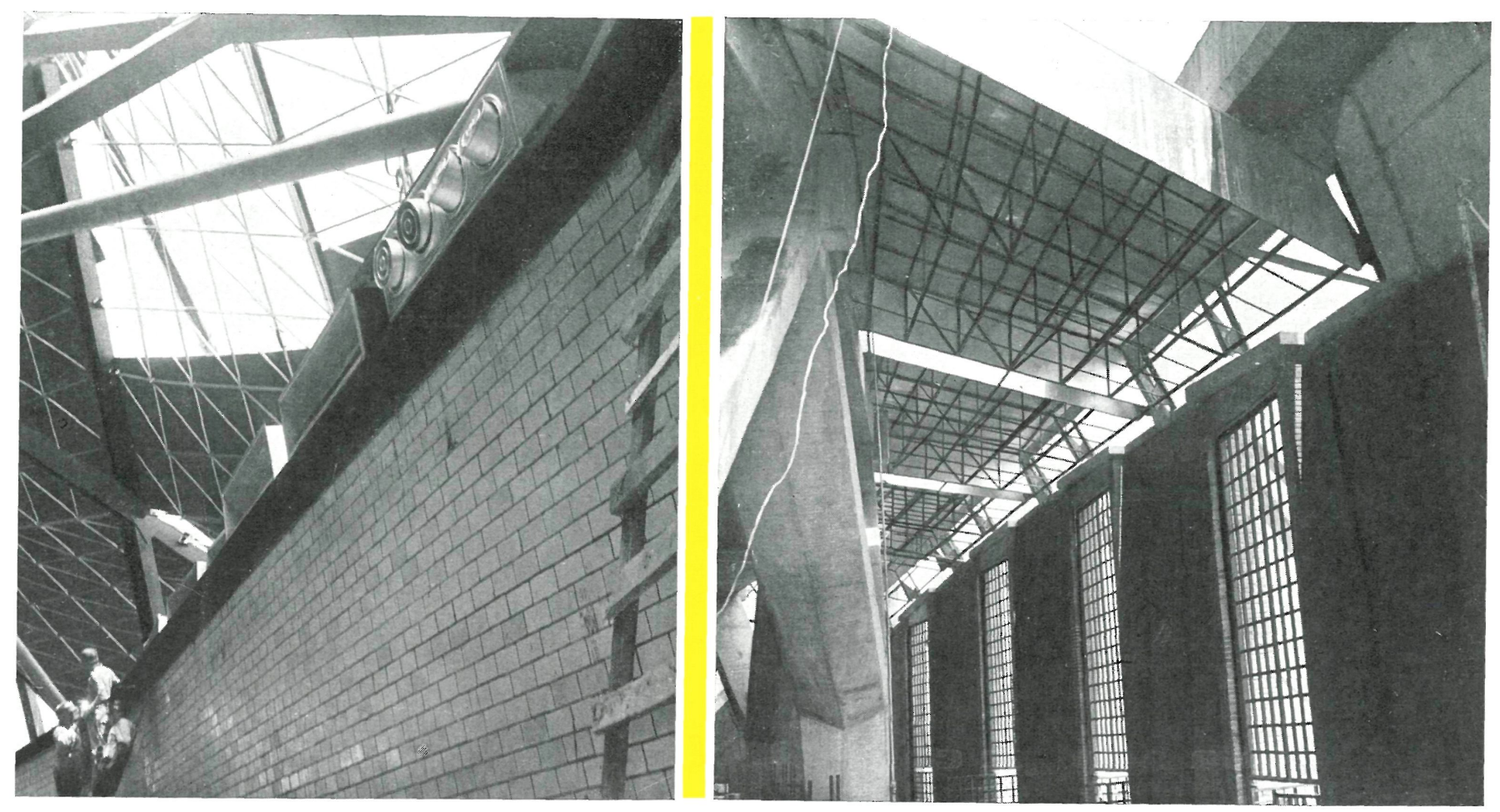

La superestructura está constituida por las graderías y las losas de forjados, de los niveles en que se alojan los servicios ya mencionados.

La losa del nivel intermedio tiene $40 \mathrm{~cm}$ de espesor y fue aligerada mediante huecos dejados en su espesor. La losa del nivel de palcos es nervada y forma huecos triangulares, que se lograron con una cimbra perdida de asbesto-cemento, lo cual proporcionó un acabado «a cara vista» magnífico.

La estructura general del edificio fue considerada, desde la fase del proyecto, como el elemento dominante de la composición, y el determinante de su sentido plástico espacial.

En particular, la estructura de la cubierta consta de una retícula ortogonal con armaduras de acero de directriz circular, que siguen la dirección de los círculos máximos de una esfera, por lo que cada una de ellas lleva, en su plano lateral, una cierta inclinación con respecto a la vertical igual a la del radio correspondiente.

Estas armaduras, en forma de arcos, tienen un peralte de $5 \mathrm{~m}$ y llevan unas cuerdas centrales que trabajan fundamentalmente a compresión.

Los huecos que van formando cada cuatro armaduras son de $12 \times 12 \mathrm{~m}$ y fueron cubiertos con paraboloides hiperbólicos constituidos por una estructura a base de tubo de aluminio, la cual, a su vez, recibe una abertura realizada con madera contrachapada, de $38 \mathrm{~mm}$, protegida por un impermeabilizante asfáltico y teja de cobre.

Los extremos de los arcos van provistos de tornapuntas de hormigón armado que los reciben y de unos tirantes de tubo que absorben los momentos que se presenten en la estructura. 
Para determinar el comportamiento de esta estructura ante la fuerza del viento fue construido un modelo a escala reducida, el cual se sometió a distintas condiciones y velocidades en un túnel de viento, habiéndose obtenido resultados interesantes que fueron después aplicados en el cálculo.

Los muros exteriores, sobre la circunferencia extrema, tienen, en su parte baja, planta en zigzag, en tanto que en su perímetro superior coinciden exactamente con el círculo correspondiente, de menor diámetro que el inferior; estos muros, de ladrillo, son además dobles, están separados entre sí y va relleno el hueco que forman con un hormigón pobre formado con «tezontle», roca volcánica muy ligera, arena y cemento portland.

Las cantidades de materiales empleados principalmente en las obras han sido las siguientes: $35.940 \mathrm{~m}^{3}$ de hormigón; $4.570 \mathrm{t}$ de hierro en armaduras; $1.080 \mathrm{t}$ de acero en las estructuras; 1.500 .000 piezas de ladrillo cerámico, y 33.000 piezas de bloques de cemento de $40 \times 40 \times 60$.

Los pavimentos fueron realizados con adoquín de piedra rosa de Querétaro y piedra basáltica negra.

En este edificio, que constituye un bello exponente dentro de los de su género, se ha logrado que, tanto exterior como interiormente, y desde cualquier punto de vista, se aprecie una plástica interesante y atractiva.

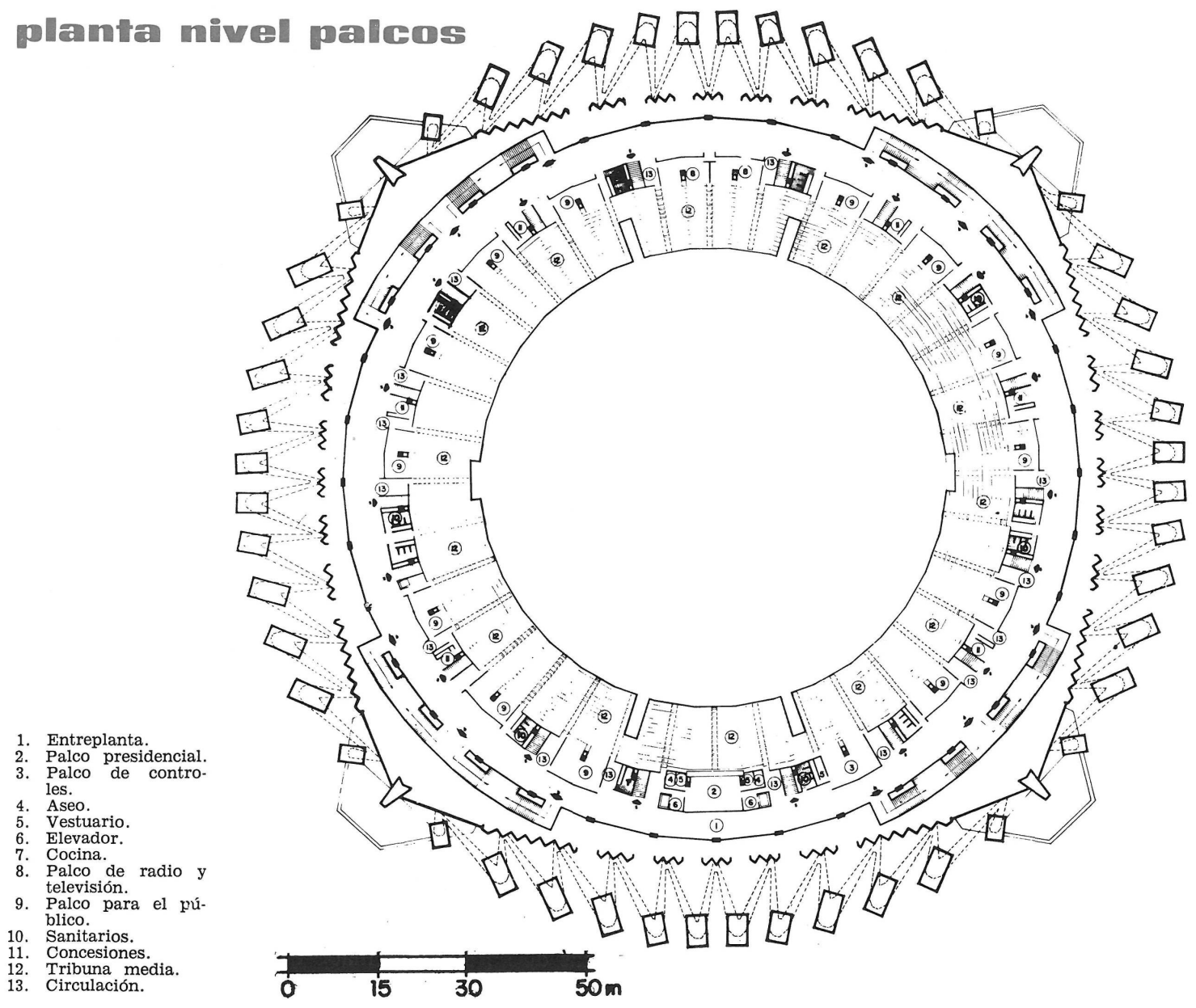

